\title{
Structural Revision and Biomimetic Synthesis of Goupiolone B
}

\author{
Yosuke Matsuo*, Ayane Yoshida, Yoshinori Saito, and Takashi Tanaka*
}

Abstract: Goupiolones A and B are unique phenolic compounds with significant DNA-damaging activity. In this study, the structure of goupiolone $B$ was revised on the basis of DFT calculations of the ${ }^{13} \mathrm{C}$ NMR chemical shifts and biosynthetic considerations. The dibenzobicyclo[3.2.2]nonane skeleton of the revised structure suggested that goupiolone $B$ was produced by oxidative coupling between catechol and goupiolone $A$, which was strongly supported by this biomimetic synthesis. Furthermore, the racemization of goupiolone B was observed during the examination for the chiral separation of its racemic mixture. A plausible racemization mechanism involving a-ketol rearrangement was also proposed.

Goupiolones A (1) and B (2) are unique phenolic compounds isolated from the leaves of Goupia glabra (Goupiaceae), and reported to show significant toxicity against a panel of DNA damage-checkpoint defective yeast mutants (Figure 1). ${ }^{[1]}$ Since 1 and 2 behave as genotoxins that are stronger than the antineoplastic agent doxorubicin, they are candidates for anticancer drugs. ${ }^{[1]}$ Goupiolone A (1) is a benzotropolone derivative $\mathrm{e}^{[1,2]}$ and presumed to be produced from catechol (3) and ethyl gallate (4) by oxidative coupling via a benzobicyclo[3.2.1]octane-type intermediate (Scheme 1). Other benzotropolone derivatives from natural sources, such as purpurogallin glycosides, ${ }^{[3]}$ theaflavins, ${ }^{[4]}$ fomentariol, ${ }^{[5]}$ aurantricholone, ${ }^{[6]}$ and crocipodin, ${ }^{[7]}$ are also produced by the coupling between catechol and pyrogallol derivatives. ${ }^{[8]}$ On the other hand, goupiolone B (2) was reported as a Diels-Alder adduct between a tropolone and a naphthalene derivative. ${ }^{[1]}$ However, the proposed precursor, that is 1,2,3,4naphthalenetetraol, has not yet been found in nature. In addition,<smiles>CCOC(=O)c1cc(O)c(=O)c2c(O)c(O)ccc2c1</smiles>

goupiolone A (1)

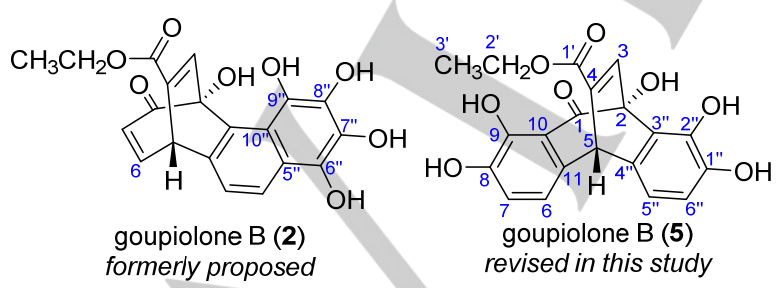

Figure 1. Structures of goupiolone A (1) and goupiolone B (2: formerly proposed $^{[1]} ; \mathbf{5}$ : revised)

[a] Dr. Y. Matsuo, A. Yoshida, Dr. Y. Saito, Prof. Dr. T. Tanaka Graduate School of Biomedical Sciences Nagasaki University

1-14 Bunkyo-machi, Nagasaki 852-8521 (Japan)

E-mail: y-matsuo@nagasaki-u.ac.jp t-tanaka@nagasaki-u.ac.jp

Supporting information for this article is given via a link at the end of the document. (a) 2

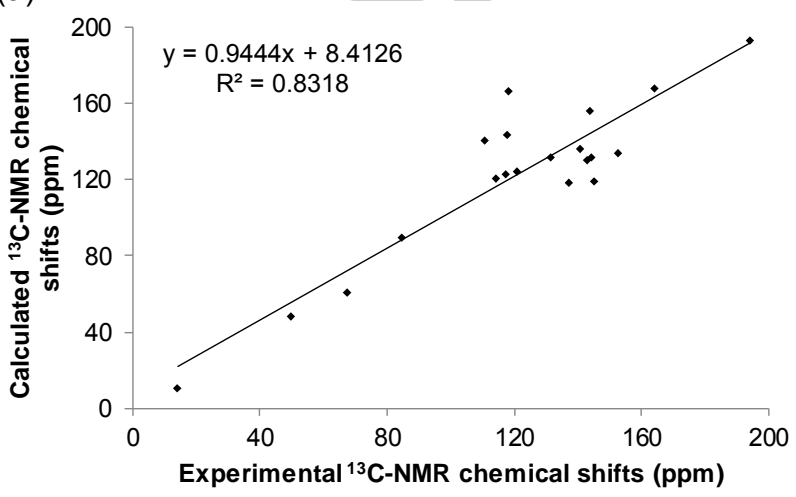

(b) 5

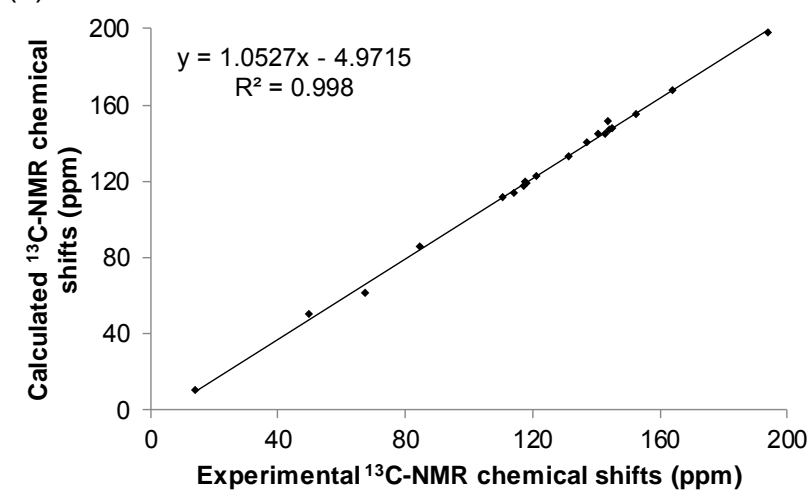

Figure 2. Correlation plots of experimental ${ }^{13} \mathrm{C}$ NMR chemical shifts versus the corresponding calculated data of $\mathbf{2}(\mathrm{a})$ or $\mathbf{5}(\mathrm{b})$.

the reported spectroscopic data of 2 include several problems. For example, the ${ }^{13} \mathrm{C}$ NMR signal of the $\beta$-position in the $\alpha, \beta$ unsaturated carbonyl is normally observed lower field, such as at $150.9 \mathrm{ppm}$ for 2-cyclohexen-1-one. ${ }^{[9]}$ However, the signal at $118.1 \mathrm{ppm}$ was assigned as the $\beta$-position (C-6) of $2^{\left[{ }^{1]}\right.}$ Moreover, the assignment of the ${ }^{13} \mathrm{C}$ NMR chemical shifts of the 1,2,3,4-tetrahydroxybenzene moiety in 2 were inappropriate (C5": $\delta$ 145.1; C-6": $\delta$ 152.5; C-7": $\delta$ 142.7; C-8": $\delta$ 140.5; C-9": $\delta$ 144.0; C-10": $\delta$ 137.0). In this study, we reinvestigated the structure of goupiolone B using computational calculations and biosynthetic considerations and proposed the revised structure $\mathbf{5}$. Furthermore, the structure was confirmed via biomimetic synthesis.

We speculated that goupiolone $B$ is biosynthetically derived from goupiolone $A(\mathbf{1})$ and reinvestigated its structure on the basis of the reported ${ }^{1} \mathrm{H}$ and ${ }^{13} \mathrm{C}$ NMR data along with biosynthetic considerations. As a result, we constructed the more reasonable structure 5 with a dibenzobicyclo[3.2.2]nonane skeleton (Figure 1). The biosynthesis of $\mathbf{5}$ could be explained as follows: Goupiolone A (1) is apparently produced by the oxidative condensation between catechol-quinone (3a) derived from catechol (3) and ethyl gallate (4) through a benzobicyclo[3.2.1]octane-type intermediate. Then, a series of intermolecular 1,4- and intramolecular 1,2-additions between $\mathbf{3 a}$ 
and 1 and the subsequent reduction of o-quinone affords 5 (Scheme 1). Furthermore, the experimental NMR data of goupiolone $B$ was very similar to those of the dibenzobicyclo[3.2.2]nonane unit of $\mathbf{6}$, which is an oxidative condensation product of theaflavin (7) and epicatechin (8) (Scheme 2). ${ }^{[11]}$ The structural similarity strongly supported the biosynthetic mechanism of $\mathbf{5}^{\left[{ }^{[11]}\right.}$ The validity of structure $\mathbf{5}$ was confirmed by DFT calculations for the ${ }^{13} \mathrm{C}$ NMR chemical shifts of $\mathbf{2}$ and $\mathbf{5}^{[10]}$ followed by comparison with the reported data. As shown in Figure 2, the correlation between experimental and calculated data for 2 was very low $\left(R^{2}=0.8318\right)$, whereas the calculated data for $\mathbf{5}$ was in good agreement with the experimental data $\left(R^{2}=0.9980\right)$. On the basis of these considerations, we performed the biomimetic synthesis of $\mathbf{5}$ from $\mathbf{3}$ and $\mathbf{4}$ via $\mathbf{1 .}$

Firstly, we synthesized goupiolone A (1). Thus far, there have been two reports for the total synthesis of 1 ; however, these methods required many steps [19 steps (2012), ${ }^{[2]} 9$ steps $\left.(2017)^{[12]}\right]$. In this study, the non-enzymatic biomimetic method developed for theaflavins, black tea pigments with a benzotropolone moiety, ${ }^{[13]}$ was applied to the synthesis of 1 . Catechol (3) was oxidized with the 2,2-diphenyl-1-picrylhydrazyl (DPPH) radical in acetone to afford o-quinone (3a); then, ethyl gallate (4) was added to give a benzobicyclo[3.2.1]octane-type intermediate. Finally, the addition of water to the reaction mixture caused ring cleavage, followed by spontaneous oxidation and decarboxylation to afford goupiolone A (1) $(34 \%$ from 4) along with a small amount of 5 (1.1\% from 4) (Scheme 3a). The spectroscopic data of synthesized 1 were in full<smiles>O=c1c(O)cc([C@H]2Oc3cc(O)cc(O)c3C[C@H]2O)cc2c([C@@H]3Oc4cc(O)cc(O)c4C[C@H](O)[C@H]3O)cc(O)c(O)c12</smiles>

theaflavin (7)

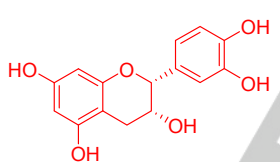

epicatechin (8) polyphenol oxidase (Japanese pear fruit homogenate)

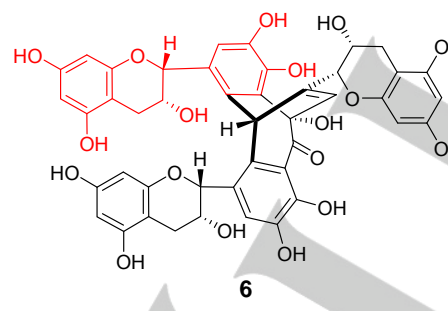

Scheme 2. Production of 6 from theaflavin (7) and epicatechin (8) using polyphenol oxidase. ${ }^{[11]}$ agreement with those of natural $1 .{ }^{[1,2]}$ In addition, the ${ }^{1} \mathrm{H}$ and ${ }^{13} \mathrm{C}$ NMR data of synthesized $\mathbf{5}$ were completely consistent with those of the natural goupiolone $\mathrm{B}$, except for the ${ }^{13} \mathrm{C}$ NMR chemical shift of C-2' $\left(\Delta \delta_{C}=5.7 \mathrm{ppm}\right)\left(\right.$ Table 1). ${ }^{[1]}$ The previously reported value of C-2' is presumably a typographical error. ${ }^{1} \mathrm{H}-{ }^{1} \mathrm{H}$ COSY, HSQC, and HMBC spectra of synthesized 5 were also measured, and the results strongly supported this structure. However, several HMBC correlations of the synthesized $\mathbf{5}$ were inconsistent with the reported data for goupiolone B (Table 1). This was probably caused by incorrect interpretations based on the incorrect structure (2) in the original report. ${ }^{[14]}$ There are several steps during the production of $\mathbf{1}$ from 3 and 4. (Scheme 1). In this process, $3 a$ derived from $\mathbf{3}$ can also act as an oxidant along with DPPH. In the final step of the synthesis of $\mathbf{5}$, the $o$-quinone form of $\mathbf{5}$ is reduced to $\mathbf{5}$ (Scheme 1). This reduction process is considered to be coupled with the oxidation of $\mathbf{3}$ or the oxidation steps during the synthesis of $\mathbf{1}$.

Enzymatic methods for the synthesis of benzotropolone derivatives using polyphenol oxidase or peroxidase are known; ${ }^{[7,15]}$ therefore, we also performed the enzymatic synthesis of goupiolone A (1). An aqueous solution of catechol (3) and ethyl gallate (4) was treated with a Japanese pear (Pyrus pyrifolia) fruit homogenate, which has strong polyphenol oxidase activity, ${ }^{[15 d, 16]}$ to afford goupiolone A (1) $(71 \%)$ along with $5(0.24 \%)$ (Scheme $3 b)$. This relatively high yield of 1 is

(a)

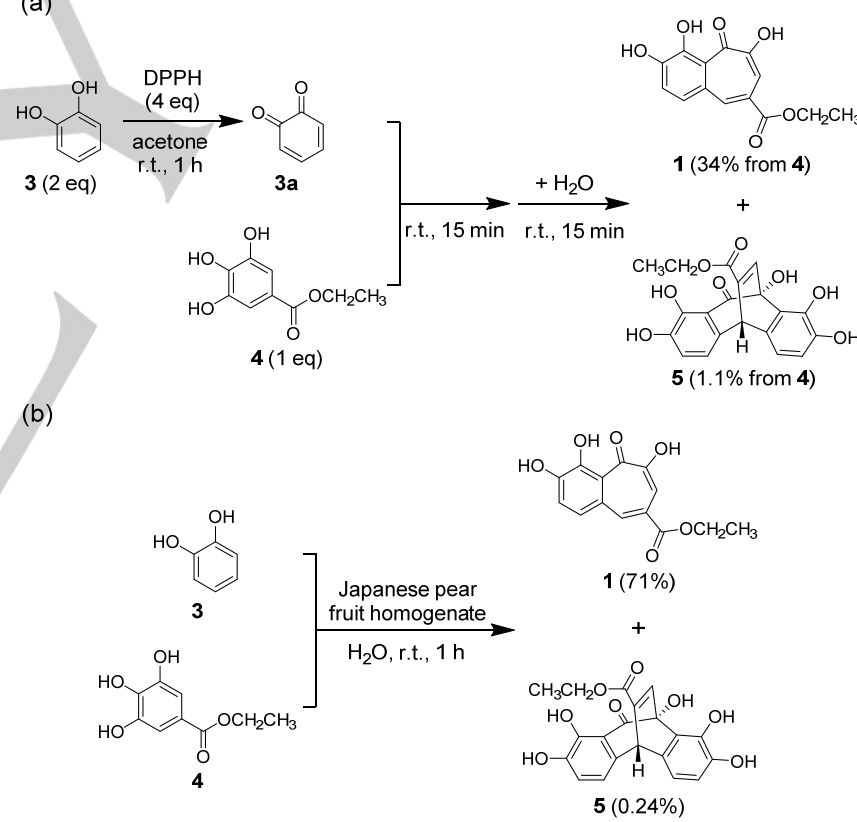

Scheme 3. Synthesis of goupiolones A (1) and B (5) from 3 and 4 using $\mathrm{DPPH}$ radical (a) or a Japanese pear fruit homogenate (b).

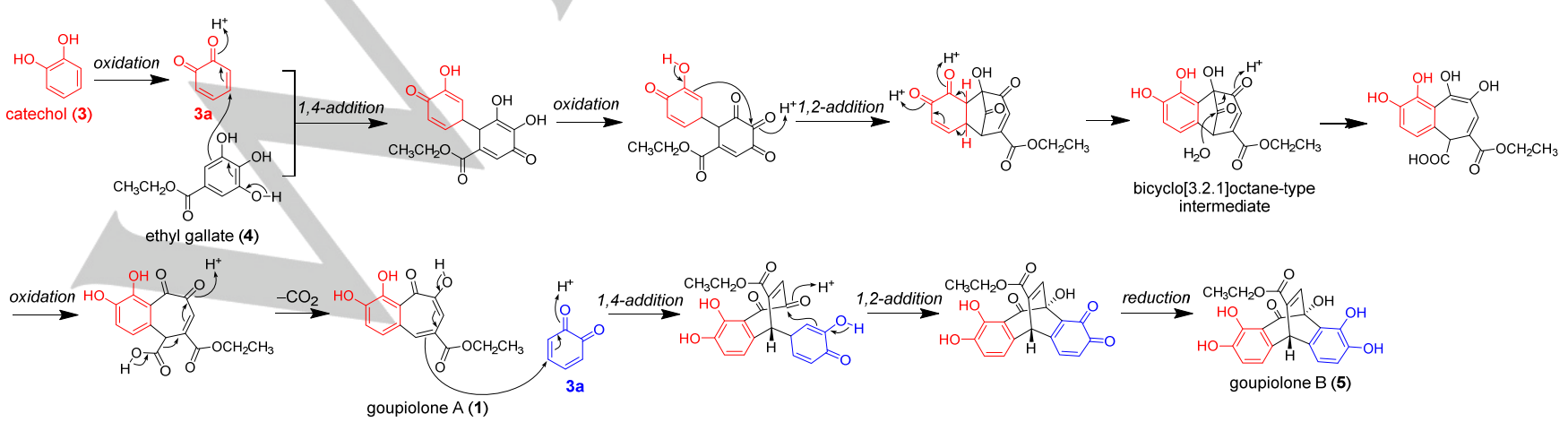

Scheme 1. Proposed biosynthetic pathway of goupiolone B (5) from catechol (3) and ethyl gallate (4) via goupiolone A (1). 
considered to be attributed to the substrate specificity of polyphenol oxidase for 3 .

To confirm that goupiolone B (5) was produced by oxidative coupling between goupiolone A (1) and catechol (3), next we examined direct reactions of $\mathbf{1}$ with $\mathbf{3}$. Addition of $\mathbf{1}$ to the mixture containing $\mathbf{3 a}$ yielded 5 in $7.2 \%$ (Scheme $4 a$ ). To improve the yield, various oxidants were examined. After screening with multiple oxidants, $\left(\mathrm{NH}_{4}\right)_{2} \mathrm{Ce}\left(\mathrm{NO}_{3}\right)_{6}$ and $\mathrm{K}_{3}\left[\mathrm{Fe}(\mathrm{CN})_{6}\right]$ were found to afford 5 from 1 and 3. The addition of $\left(\mathrm{NH}_{4}\right)_{2} \mathrm{Ce}\left(\mathrm{NO}_{3}\right)_{6}$ to a solution containing 1 and $\mathbf{3}$ in $\mathrm{CH}_{3} \mathrm{CN}-\mathrm{H}_{2} \mathrm{O}$ (4:1) afforded 5 in $22 \%$ yield (Scheme $4 \mathrm{~b}$ ). Under similar (a)

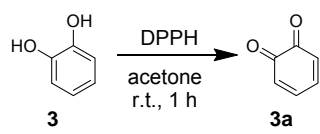

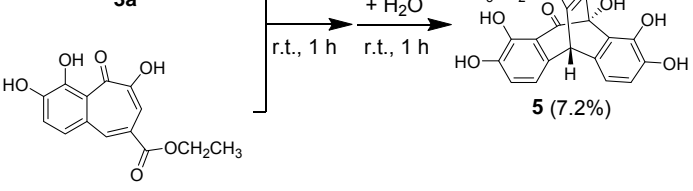

(b)

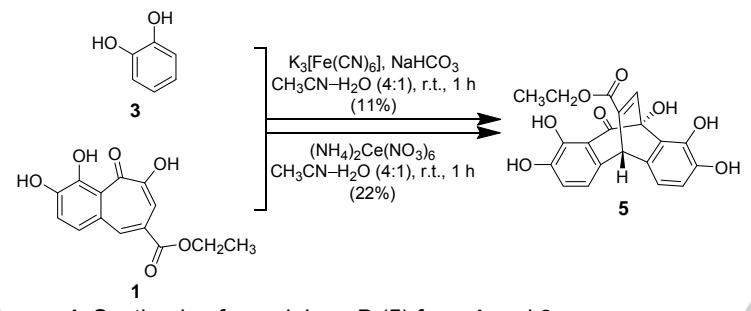

Scheme 4. Synthesis of goupiolone B (5) from 1 and 3.

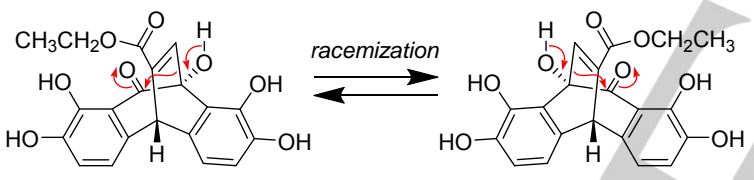

Scheme 5. Plausible racemization mechanism of goupiolone B (5). conditions, oxidation using $\mathrm{K}_{3}\left[\mathrm{Fe}(\mathrm{CN})_{6}\right]$ afforded 5 in $11 \%$ yield The reason for the low yield for $\mathbf{5}$ is considered to be the other oxidation reaction of 1 and further oxidation of $\mathbf{5}$. These results confirmed that $\mathbf{5}$ was produced from $\mathbf{1}$ and $\mathbf{3}$. Therefore, we concluded that the correct structure of goupiolone B is $\mathbf{5}$.

In this study, goupiolone B (5) was synthesized as a racemic mixture. However, natural $\mathbf{5}$ was optically active $\left([\alpha]^{20}{ }_{D}\right.$ $-40){ }^{[1]}$ To determine the absolute structure of natural 5 , an attempt was made to separate two enantiomers of synthesized $\mathbf{5}$ using chiral HPLC. Several conditions were found for the chiral separation of racemic 5 in reversed phase and normal phase conditions, which afforded two separated peaks (Figures S1, S2). However, separated $\mathbf{5}$ showed no optical rotation and Cotton effect in the ECD spectra. In addition, the reanalysis of separated $\mathbf{5}$ using chiral column exhibited two peaks, indicating that the racemization of $\mathbf{5}$ occurs easily. To comprehensively investigate the condition, chiral separation was performed at three different temperatures $\left(40{ }^{\circ} \mathrm{C}, 25^{\circ} \mathrm{C}\right.$, and $\left.5{ }^{\circ} \mathrm{C}\right)$ using Chiralpak IB N-5 (n-hexane-2-PrOH-TFA; 55:45:0.1) (Figure S3). Two peaks were completely separated at a temperature of $5{ }^{\circ} \mathrm{C}$; however, a saddle-shaped curve was observed between two peaks at $40^{\circ} \mathrm{C}$. The experimental results strongly indicated the occurrence of racemization of $\mathbf{5}$ during chiral separation at $40{ }^{\circ} \mathrm{C}$. A reasonable mechanism for the racemization of 5 involves a-ketol rearrangement shown in Scheme $5 .{ }^{[17,18]}$ This rearrangement had been observed in several natural products. ${ }^{[19]}$ Natural 5 may also be a racemic mixture, and its optical activity may be attributable to its impurity. However, no evidence is currently available.

In summary, we proposed the correct structure of goupiolone B (5), which was assisted by biosynthetic considerations. DFT calculations of the ${ }^{13} \mathrm{C}$ NMR chemical shifts strongly supported this structure. The biomimetic synthesis of 5 from catechol (3) and ethyl gallate (4) via goupiolone A (1) confirmed the revised structure. Furthermore, the racemization of $\mathbf{5}$ was observed during its chiral separation, indicating that natural $\mathbf{5}$ may also be a racemic mixture. A plausible racemization mechanism involving $\alpha$-ketol rearrangement was

Table 1. ${ }^{1} \mathrm{H}$ and ${ }^{13} \mathrm{C}$ NMR data for goupiolone $\mathrm{B}(5)$ (in $\mathrm{CDCl}_{3}$, $\delta$ in ppm, $\mathrm{J}$ in $\mathrm{Hz}$ )

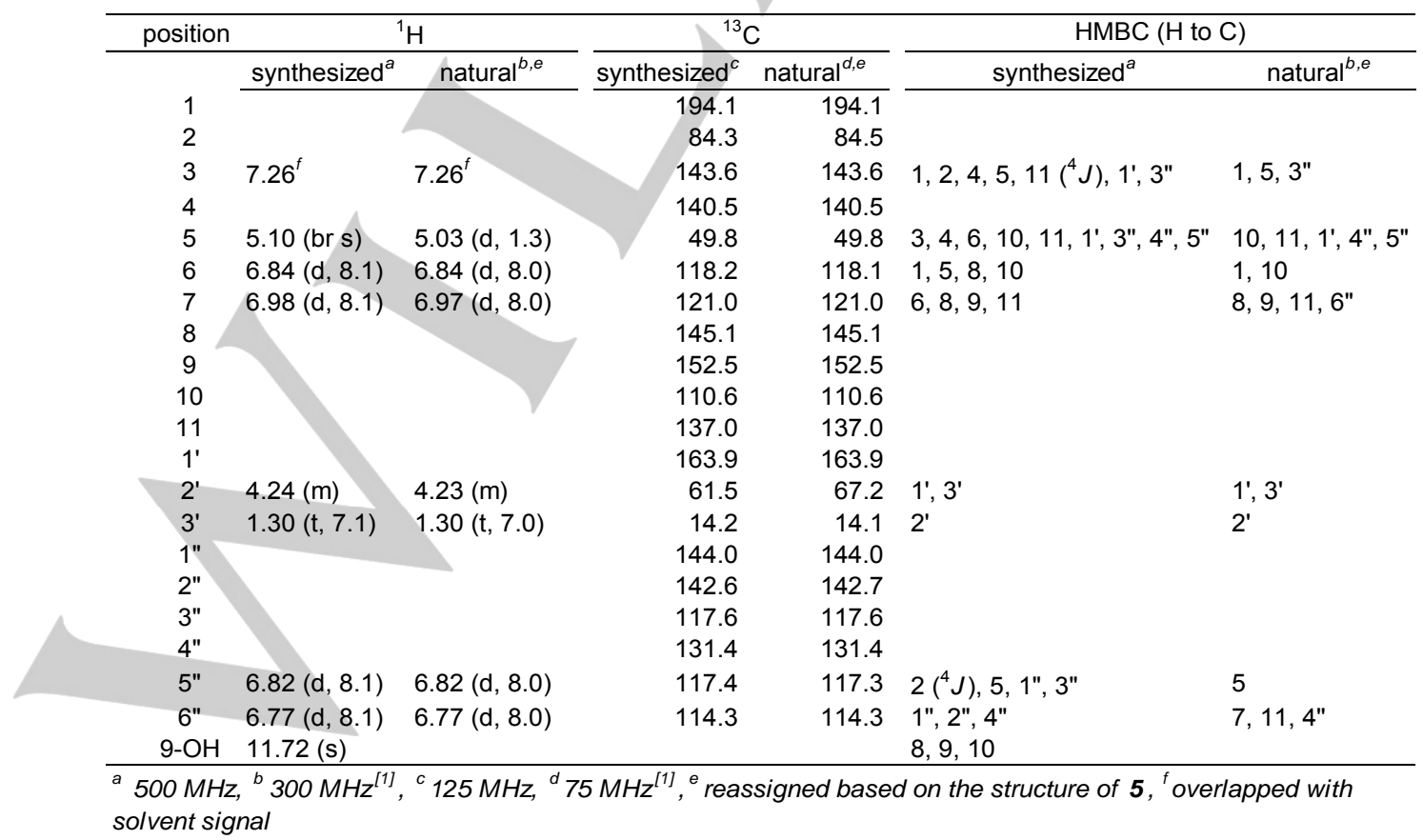


proposed. These results indicated that the biosynthetic consideration combined with the theoretical calculation of NMR data is helpful to accurately elucidate the complicated structure of natural products. ${ }^{[20]}$

\section{Acknowledgements}

This work was supported by JSPS KAKENHI Grant Numbers JP16K07741 and JP17K08338. The authors are grateful to Mr. K. Inada and Mr. N. Tsuda (Center for Industry, University and Government Cooperation, Nagasaki University) for collecting NMR and MS data, and Dr. M. Tanaka (Graduate School of Biomedical Sciences, Nagasaki University) for providing access to the ECD spectrometer. The authors also thank Daicel Corporation for chiral HPLC analysis. The computation was partly carried out using the computer facilities at the Research Institute for Information Technology, Kyushu University. The authors would like to thank Enago (www.enago.jp) for the English language review.
2004, 12, 459-467; d) T. Tanaka, C. Mine, K. Inoue, M. Matsuda, I. Kouno, J. Agric. Food Chem. 2002, 50, 2142-2148.

[16] M. Nishimura, C. Fukuda, M. Murata, S. Homma, J. Sci. Food Agric. 2003, 83, 1156-1162.

[17] L. A. Paquette, J. E. Hofferberth, Organic Reactions 2003, 62, 477-567.

[18] Biosyntheses of several natural products are considered to be associated with $\alpha$-ketol rearrangement: a) A. Kawamura, M. Kita, H. Kigoshi, Angew. Chem. Int. Ed. 2015, 54, 7073-7076; Angew. Chem. 2015, 127, 7179-7182; b) M. Kita, A. Kawamura, H. Kigoshi, Tetrahedron Lett. 2016, 57, 858-860; c) Y. Tian, Q. Guo, W. Xu, C. Zhu, Y. Yang, J. Shi, Org. Lett. 2014, 16, 3950-3953; d) S. Yin, C.-Q. Fan, X.-N. Wang, L.-P. Lin, J. Ding, J.-M. Yue, Org. Lett. 2006, 8, 49354938; e) P. J. Proteau, Y. Li, J. Chen, R. T. Williamson, S. J. Gould, R. S. Laufer, G. I. Dmitrienko, J. Am. Chem. Soc. 2000, 122, 8325-8326.

[19] a) J. J. Brophy, D. C. Craig, R. J. Goldsack, C. J. R. Fookes, D. N Leach, P. G. Waterman, Phytochemistry 2006, 67, 2085-2089; b) E. Nishimura, Y. Ohfune, T. Shinada, Tetrahedron Lett. 2015, 56, 539-541.

[20] Selected examples for structural revisions of natural products based on biosynthetic considerations: a) P. D. Brown, A. C. Willis, M. S. Sherburn, A. L. Lawrence, Angew. Chem. Int. Ed. 2013, 52, 13273-13275; Angew. Chem. 2013, 125, 13515-13517; b) J. T. J. Spence, J. H. George, Org Lett. 2011, 13, 5318-5321.

\section{Conflict of interest}

Authors declare no conflict of financial interest.

Keywords: natural products $\cdot$ biomimetic synthesis $\cdot$ structure elucidation $\bullet$ oxidation $\cdot$ rearrangement

[1] D. Mesa-Siverio, A. Estévez-Braun, Á. G. Ravelo, J. R. Murguia, A. Rodríguiz-Afonso, Eur. J. Org. Chem. 2003, 4243-4247.

[2] N. Fukui, K. Ohmori, K. Suzuki, Helv. Chim. Acta 2012, 95, 2194-2217.

[3] a) M. Nierenstein, A. Swanton, Biochem. J. 1944, 38, 373-375; b) J. A. Barltrop, J. S. Nicholson, J. Chem. Soc. 1948, 116-120.

[4] a) Y. Takino, H. Imagawa, H. Horikawa, A. Tanaka, Agric. Biol. Chem. 1964, 28, 64-71; b) Y. Takino, H. Imagawa, Agric. Biol. Chem. 1964, 28 255-256; c) Y. Takino, A. Ferretti, V. Flanagan, M. Gianturco, M. Vogel, Tetrahedron Lett. 1965, 6, 4019-4025; d) P. D. Collier, T. Bryce, R. Mallows, P. E. Thomas, D. J. Frost, O. Korver, C. K. Wilkins, Tetrahedron 1973, 29, 125-142.

[5] N. Arpin, J. Favre-Bonvin, W. Steglich, Phytochemistry 1974, 13, 19491952.

[6] D. Klostermeyer, L. Knops, T. Sindlinger, K. Polborn, W. Steglich, Eur. J. Org. Chem. 2000, 603-609.

[7] L. Kerschensteiner, F. Lobermann, W. Steglich, D. Trauner, Tetrahedron 2011, 67, 1536-1539.

[8] E. Yanase, K. Sawaki, S. Nakatsuka, Synlett 2005, 2661-2663.

[9] SDBSWeb: http://sdbs.db.aist.go.jp (National Institute of Advanced Industrial Science and Technology, accessed May 16, 2017).

[10] a) M. W. Lodewyk, M. R. Siebert, D. J. Tantillo, Chem. Rev. 2012, 112, 1839-1862; b) P. H. Willoughby, M. J. Jansma, T. R. Hoye, Nat. Protoc. 2014, 9, 643-660; c) N. Grimblat, A. M. Sarotti, Chem. - Eur. J. 2016 , $22,12246-12261$

[11] Y. Li, A. Shibahara, Y. Matsuo, T. Tanaka, I. Kouno, J. Nat. Prod. 2010, 73, 33-39.

[12] D. Arican, S. Braukmüller, R. Brückner, Chem. - Eur. J. 2017, 23, 4537-4541.

[13] Y. Matsuo, R. Oowatashi, Y. Saito, T. Tanaka, Synlett, DOI: 10.1055/s0036-1588529.

[14] In reference 1, HMBC correlations of goupiolone $B$ were described; however, its copy of the HMBC spectrum was not shown.

[15] a) K. Cheng, X. Wang, S. Zhang, H. Yin, Angew. Chem. Int. Ed. 2012 51, 12246-12249; Angew. Chem. 2012, 124, 12412-12415; b) G. Baisch, B. Wagner, R. Öhrlein, Tetrahedron 2010, 66, 3742-3748. c) S Sang, J. D. Lambert, S. Tian, J. Hong, Z. Hou, J.-H. Ryu, R. E. Stark, R. T. Rosen, M.-T. Huang, C. S. Yang, C.-T. Ho, Bioorg. Med. Chem. 


\section{COMMUNICATION}

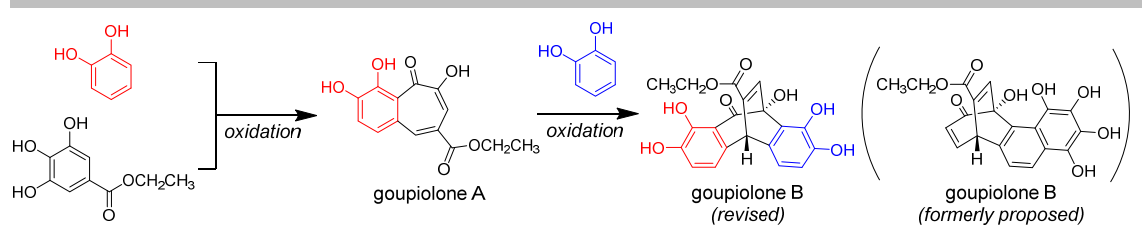

Yosuke Matsuo, * Ayane Yoshida

Yoshinori Saito, Takashi Tanaka*

Page No. - Page No.

Structural Revision and Biomimetic Synthesis of Goupiolone B

Which one is real? Goupiolones A and B are unique phenolic compounds with significant DNA-damaging activity. In this study, the structure of goupiolone B was revised on the basis of DFT calculations of the ${ }^{13} \mathrm{C}$ NMR chemical shifts and biosynthetic considerations. The dibenzobicyclo[3.2.2]nonane skeleton of the revised structure suggested that goupiolone $B$ is produced by an oxidative coupling between catechol and goupiolone $A$. This revised structure and proposed biosynthetic pathway was strongly supported by the biomimetic synthesis. 